Provence. The paper is divided into three parts, the first of which describes theoretical relations between the measurable intensities of the lines and the values of the electronic temperature; and the second deals with electronic temperatures deduced from the intensities of the lines of [O III] measured by the photographic spectrophotometer. Of the two methods mentioned, that using the hydrogen lines allows the extension of the study to feinter nebulae. Twenty-four planetary nebulae were studied and the electronic temperatures obtained ranged between $8,000^{\circ}$ and $27,000^{\circ} \mathrm{K}$. Comparison of these results with those obtained by others, in particular the photo. electric measurements of Liller and Aller, have led to disagreements which can be explained by taking into consideration the magnitudes of the monochromatic images. From the intensities of hydrogen and helium lines, a correlation is shown to exist between the electronic temperatures and the extent of ionization of the nebula, characterized by the intensity of the helium lines. The third part deals with the continuous spectrum and the Balmer discontinuity of six planetary nebulae, and the experimental results are compared with those of Cillié and of Spitzer and Greenstein. The former give electronic *emperatures which are too high, whereas those of :Spitzer and Greenstein give temperatures which are too low. Seaton's theory provides results which are in satisfactory agreement, with the exception of N.G.C. 7662, but it is pointed out that his adoption of $13,000^{\circ} \mathrm{K}$. for this nebula is inaccurate. It is admitted that, as Seaton has shown (Mon. Not. Roy. Astro. Soc., 114, $154 ; 1954)$, it is elso possible to compute electronic temperatures starting with the intensities of other forbiddon lines.

\section{Space-Group Theory}

OF the many $X$-ray erystallographers who utilize space-group theory in their structure analyses, few have had a systematic training in this theory, and still fewer have read the classical works of Federov, Schoenflies and Barlow in which the 230 space groups are formally derived; most are content to turn to the standard works of reference, such as the "International Tables for X-ray Crystallography", in which the space groups are tabulated without derivation and without emphasis on their interrelationships. In order to meet this difficulty, N. V. Belov published in 1951 (Trudy Inst. Krist. Acad. Nauk. SSSR, 6, 25) a 'class-room method' of deriving all the space groups in a systematic manner, based on his teaching experience in the University of Gorkii. This article has now been made available in English in the form of a translation by V. Balashov (Proc. Leeds Phil. Lit. Soc., 8, 1 ; 1957). Belov's treatment is inspired by the work of Wulff, who directed attention to the fundamental role of planes of symmetry. Starting from this point, Belov derives the 230 space grours, not in the formal sequence of the crystal classes but in an order better adapted to didactic purposes and better suited to bring into prominence the connexions between related groups. The interrelationships of symmetry elements, seemingly so simple, are in fact so subtle that any crystallographer who reads this article is bound to find in it many new ideas and many familiar ideas presented in a new and stimulating guise. The article is an admirable complement to the many other works on space-group theory already available, and its appearance in English translation is most welcome. Offprints of the trans- lation are available at a price of $7 s .6 d$. or 1.50 dollars from Austick's Bookshop, 172 Woodhouse Lane, Leeds 2.

\section{Paul Instrument Fund Committee Grants}

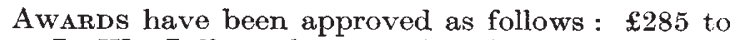
Dr. J. W. Jeffery, lecturer in physics, Birkbeck College, London, to enable him to carry out crystal structure determination by X-ray diffraction using an instrument for one-dimensional Fourier syntheses employing dekatron counting tubes. $£ 2,000$ to Prof. J. D. McGee, professor of instrument technology, Imperial College of Science and Technology, London, to enable him to construct a television system for $\mathrm{X}$-ray image intensification. $£ 11,000$ to Dr. V. E. Cosslett, university lecturer in physics, Cambridge, for the further development and improvement of the $\mathrm{X}$-ray microscope: by extending the resolution beyond that of the optical microscope and by attaching an automatic recording mechanism for quantitative analysis of elements. The Paul Instrument Fund Committee, composed of representatives of the Royal Society, the Physical Society, the Institute of Physics and the Institution of Electrical Engineers, was set up in 1945 "to receive applications from British subjects who are research workers in Great Britain for grants for the design, construction and maintenance of novel, unusual or much improved types of physical instruments and apparatus for investigations in pure or applied physical science".

\section{Ramsay Memorial Fellowships Awards}

The Ramsay Memorial Fellowships Trustees have awarded fellowships in chemistry for 1958-59 as follows: Mr. G. S. Laurence, a general fellowship at the University of Leeds; a French fellowship to Mme. Mousseron Canet at the Imperial College of Science and Technology, London; a Spanish fellowship to Dr. J. Rodriguez Martinez, at the Atomic Energy Research Establishment, Harwell, and Rothamsted Experimental Station; a United States fellowship to Mr. Phillip G. Thompson at the University of Cambridge. The Trustees have renewed the following fellowships for the same year: Mr. T. E. Peacock (general fellowship) at the University College of North Stafforshire; Dr. D. McK. Wiles (Canadian fellowship) at the University of Leeds; Dr. M. Masui (Japanese fellowship) at University College, London; Mr. J. E. Fergusson (New Zealand fellowship) at University College, London; $\mathrm{Mr}$. P. Arambarri (Spanish fellowship) at Rothamsted Experimental Station; Dr. Diaz Pena (Spanish fellowship) at the University of Reading; Mr. D. Rodriguez (Spanish fellowship) at the University of Sheffield.

\section{Animal Hea!th Trust Awards, 1958-59}

The Animal Health Trust has announced the following senior awards for the period 1958-59. Wellcome Fellowship: Mrs. H. E. Rose, to investigate the relationship between various members of the Coccidia, using immunological techniques, and to extend the present work on the immune responses of rabbits to $\boldsymbol{E}$. stiedae, to the immune responses, if any, of poultry to their coccidia. This work will be carried out at the Department of Animal Pathology, Cambridge, and afterwards at the Houghton Poultry Research Station, Huntingdonshire. Research Training Scholarships: Mr. B. A. Baldwin (Royal Veterinary College, London), to develop methods of assessing the state of consciousness and sensory per- 